\title{
Experimental evidence for oxygen isotopes diffusion in zircon
}

\author{
Pilar MONTERO $^{1}$ : Fernando BeA ${ }^{1}$; Jose F. Molina ${ }^{1}$; \\ IRENE MORALES $^{1}$ : AITOR CAMBESES ${ }^{1}$
}

Dept. Mineralogy and Petrology, Univ. of Granada, Spain; pmontero@ugr.es; fbea@ugr.es; ifmolina@ugr.es; acambeses@ugr.es

We studied experimentally the diffusion of Oxygen isotopes between natural zircon and synthetic cristobalite using open alumina crucibles within an $\mathrm{N}_{2}$ atmosphere. The crucibles $(12 \times 14 \mathrm{~mm})$ were filled with a $5 \mathrm{~mm}$ thick bed of cristobalite on top of which we placed about 100 zircons grains covered with another $5 \mathrm{~mm}$ thick cristobalite layer and pressed with a steel piston. The crucibles were transferred to a tube furnace capable of sustaining $1600{ }^{\circ} \mathrm{C}$ for long periods. The experiments were carried out at $1400^{\circ} \mathrm{C}$ over 30 days, 90 days, and 180 days on zircons from a $318 \pm 2$ Ma tonalite with a remarkably uniform oxygen isotopes composition, $\partial^{18} \mathrm{O}=6.89 \pm 0.0 .28$ ranging from 6.42 to 7.50 . The embedding cristobalite has $\partial^{18} \mathrm{O}=4.95 \pm 0.31$, ranging from 4.35 to 5.21. Figure 1 shows how the oxygen isotope composition of the heated zircons changes with time. After 30 days, the distribution widens and becomes asymmetric, tailed to the lower side. The tendency increases with time; after 180 days, the mean $\partial^{18} \mathrm{O}$ is $6.28 \pm 0.83$ and range expanded from 4.6 to 7.5. Despite these experiments being subject to the potential interference from traces of atmospheric oxygen $(218 \mathrm{O}=23.5)$, they show unequivocally that at high $\mathrm{T}$, the oxygen isotope composition of zircon inclusions drifts quickly to that of their host.

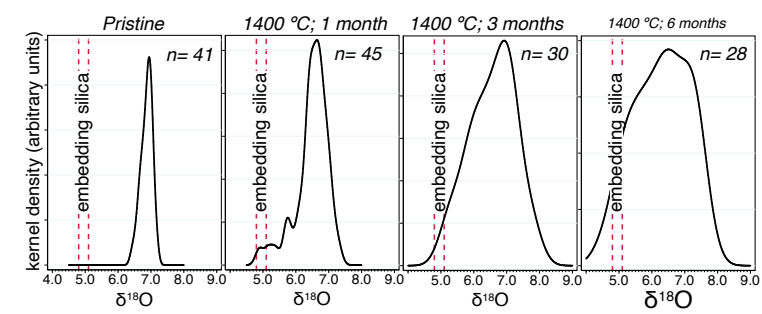

These results agree with the numerical 3D models based on Watson and Cherniak (1997) Arrhenius relation for dry Oxygen diffusion. These calculations show that a $60 \times 70 \times$ $130 \mu \mathrm{m}$ high $\partial^{18} \mathrm{O}$ zircon xenocryst surrounded by a host mineral with low, mantle-like $\partial^{18} \mathrm{O}$ only requires $0.05 \mathrm{Myr}$ at $1100{ }^{\circ} \mathrm{C}$, or $0.5 \mathrm{Myr}$ at $1000{ }^{\circ} \mathrm{C}$, to homogenize with its environment. Further studies are required to understand the Oxygen diffusion quantitatively in zircon inclusions. However, both experimental data and numerical models unequivocally suggest that zircon xenocryst with high $\partial 180$ found in mantle rocks cannot have dwelled within them at mantle temperatures for a long time.

Watson, E. B., \& Cherniak, D. J. (1997). Earth and Planetary Science Letters, 148(3-4), 527-544. 